\title{
Demand and Response in Smart Grids for Modern Power System
}

\author{
Muhammad Qamar Raza ${ }^{1}$, Muhammad Usman Haider' ${ }^{1}$ S. Muhammad Ali ${ }^{2}$, \\ Muhammad Zeeshan Rashid ${ }^{3}$, Farooq Sharif ${ }^{1}$ \\ ${ }^{1}$ Department of Electrical Engineering, The University of Faisalabad, Faisalabad, Pakistan; ${ }^{2}$ Department of Electrical Engineering, \\ COMSATS Institute of Information Technology, Abbottabad, Pakistan; ${ }^{3}$ Department of Electrical Engineering, Islamia University of \\ Bahawalpur, Bahawalpur, Pakistan. \\ Email: qamar_raza786@yahoo.com, Mohammad-ali@live.com,Chzeeshan@gmail.com
}

Received September $10^{\text {th }}, 2012$; revised February $4^{\text {th }}, 2013$; accepted February $11^{\text {th }}, 2013$

Copyright (C) 2013 Muhammad Qamar Raza et al. This is an open access article distributed under the Creative Commons Attribution License, which permits unrestricted use, distribution, and reproduction in any medium, provided the original work is properly cited.

\begin{abstract}
Micro-grid plays a vital role in fulfilling the increasing demand by using distributed renewable energy resources. Demand and response technique can be broadly classified under the setup DR deployed (e.g. ISO's/RTO's). Demand response program can be implemented to improve power system quality, reliability and increasing demand. In modern power industry, strategic player can take more benefit from more emphasized DR study in terms of social benefit (uninterrupted power supply to consumers) and economy. This paper proposes the distributed micro-grid control and implemented control setup implemented demand response algorithm, which provides better power system reliability. This paper presents contingencies control demand and response for micro-grid. The main advantage of implementation of demand and response algorithms in Micro-grids provides reliable power supplies to consumers. The proposed micro-grid TCP/IP setup provides a chance to respond the contingencies to recover the shed to active condition. Micro-grid controller implements demand and response algorithm reasonable for managing the demand of the load and intelligent load scheme in case of blackout.
\end{abstract}

Keywords: Demand Response (DR); Micro-Grid (MG); Power System Reliability; Distributed Generation (DG); Renewable Energy Resources (RER); Power System Contingencies

\section{Introduction}

Power supply is the one basic requirement to operate the machine or devices. As technology advances, the need of power is increasing drastically. Centralized power systems for generation thus produces fluctuations at load side as demand is not being fulfilled properly and this basic need is increasing rapidly. Thus utilities feel a great pressure on them for an increasing generation [1] and transmission lines. Consumers are not satisfied fully with the present scenario of available power especially in developing countries. So, Distributed Generation is one of the basic means of generating power for a certain locality, which is environmentally friendly as it minimizes the emissions of hazardous gases. MG consists of power generators capable of power generation rang from several KW to a few MW using Renewable Energy Resources such as solar, wind, biomass etc. and can run on fossil fuels such as coal, gas, oil etc. Operation of Micro Grids can be performed in two basic modes. One form of op- eration is in autonomous mode and other form of operation is in nonautonomous mode.

In power system planning and operation, Demand Responses are one of the most important factors. Currently modern power system smart grids in new emerging technology using Renewable Energy Resources (RER) plays a vital role in fulfilling current energy demand. Currently different demand response distribution schemes are widely implemented and distribution voltage reduction is one of them. In this paper, demand response impact on smart grids is discussed and renewable energy technologies (bio-gas, solar cell, wind energy) is used to propose algorithm fulfill increasing demand of power. Basically micro-grid is a form of smart grids which provides power (normally in $\mathrm{KW}$ ) to load controlled by the intelligent energy management system.

\section{Objectives of Demand Response}

- Decrees in the generation need, under this objective 
sum of demand and losses are reduced in distribution and transmission in power system. Different factors effect on this objective like cost of generation, availability of energy resources, and overall system reliability.

- Increase the overall system reliability, under this objective maintain a balance between demand and supply of power to load in different time intervals.

- Elimination of overloads from power systems, under this objective of overflow of current is reduced by Advance Energy Management System (EMS).

\section{Proposed Demand Response Micro-Grid Network}

In this paper proposed demand and response algorithm can be implemented on non-autonomous micro-grid mode of operation. In non-autonomous mode which MG acts as a standby system with electrical utilities. These DG sets are installed with electric utility to provide strength $[2,3]$ to the power plant by supporting its voltage level or by supporting power for reducing the peak demand during certain times. Stand-by power generating units with present electrical infrastructure can be used for micro-grids. MG can prove to be one of the best choices for installing it in a certain locality, provided that it costs low and also provides a certain acceptable level of reliability [4] for a fighting with present electrical utilities in the modern age. The trends of MG are enormously rising as they share some basic load from the utility. This basic trend is growing especially growing in developing countries where RER is sufficient to generate the demands of people alone as well as by sharing with utility. The basic and the foremost specialty of MG is that they can operate in Islanding mode [5] thus provides safety against troubling effects of faults.

\subsection{Demand Response Power Flow Network}

In proposed power and control Demand and Response power network show in Figure 1. Micro-Grid Central Controller (MGCC) is the link between Electrical utility and load through Local controller. Renewable Energy Resource (RER) and other small power production resources are connected to local Controller and supply the power to own connected load. Power is supplied to load from own power generation.

\subsection{TCP/IP Control Network}

In decentralized approach, DG source controller [6] is mainly responsible for power management. The DG source controller is called local controller and micro-grid central controller is connected to the local controller for power management from main utility. In Figure 2, intel-

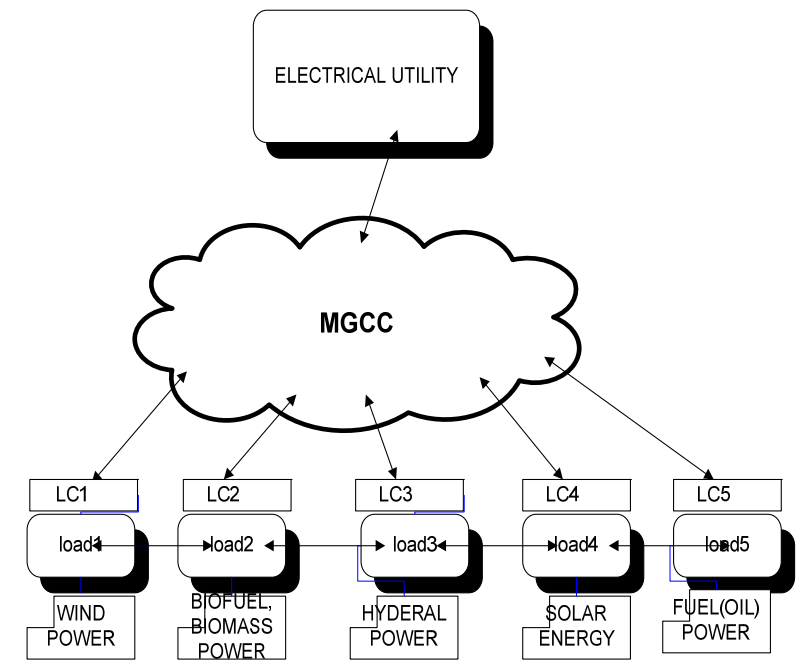

Figure 1. Distributed renewable energy resource micro-grid setup.

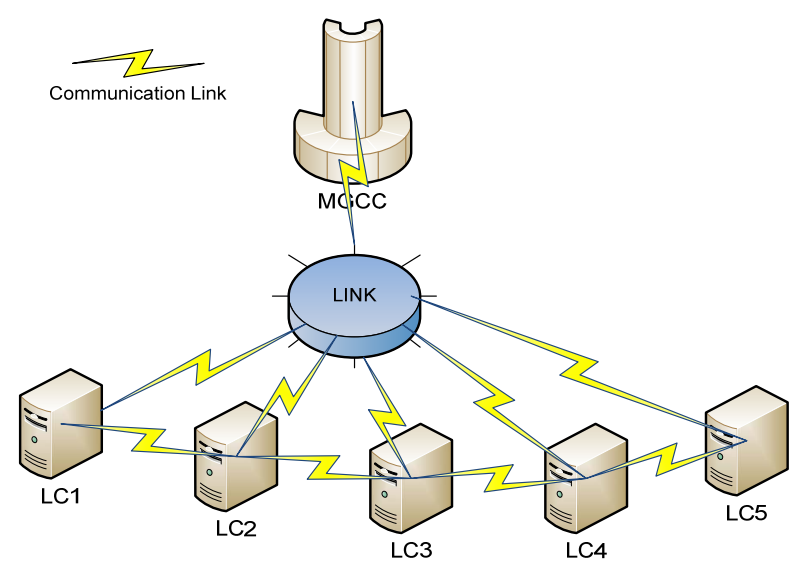

Figure 2. Micro-grid control network.

ligent TCP/IP controller network figure electrical utility is connected through Micro-Grid Central Controller (MGCC) and Local Controller (LC).

In peak hour of demand intelligent local controller which is connected by TCP/IP networking cable sends request to micro-grid central controller through TCP/IP communication protocol.

In Figure 2 TCP/IP controller network intelligent MGCC checks the available power from utility that can supply to load through local controller and local controller control the power supply to the load. If power required to load is available power that can be supplied to load then MGCC send a signal to.

Local controller starts sending power to load through LC. If more power required than local controller send requests to other local controller to send the power. In case of power requirement is not fulfill then intelligent local controller.

Perform intelligent load shedding. The ultimate objec- 
tive providing the smooth and reliable power supplied to load in different circumstances. Different types of "intelligent load shedding” [7-10] scheme have been discussed in literature for power management. In [11] describe the decentralized software control approach with intelligent agents the on FIPA software where the local controllers compute one another to optimize MGCC operation of the MG.

\section{Demand Response Algorithm}

The primary components of demand response algorithm show in the flow chart shown in Figure 3.

1) Micro-Grid Central Controllers (MGCC) checks the connected Local controller by sending connectivity command using TCP/IP protocol.

2) Micro-Grid Central Controller (MGCC) maintains the database of Local Controller (LC) connected load peak hour and normal hour power demand.

3) Local Controller (LC) compares the current demand and supply of power to load attached to the local controller (LC). If demand is greater than response power supply then local controller send a request to Micro-Grid Central Controller (MGCC) to send the required power and if demand is less than the supply then send an update request of a database of available power for MGCC.

4) If the Micro-Grid Central Controller (MGCC) can not fulfill the current demand of local controller connected load then MGCC performs intelligent load shedding.

5) MGCC performs intelligent load shedding by shed

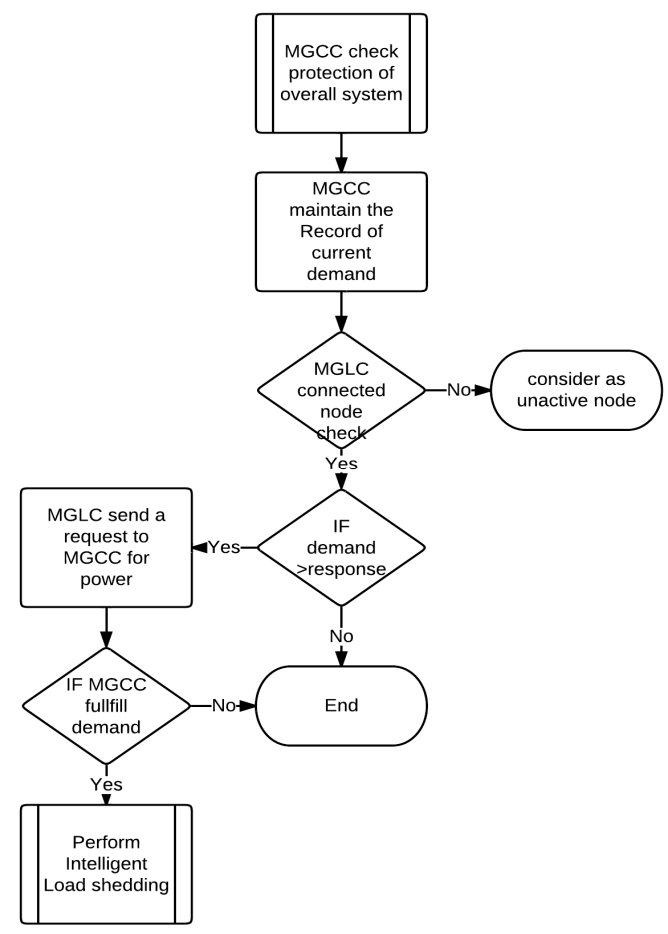

Figure 3. Demand response micro-grid algorithm. down the low priority local controller loads then 2nd least priority load and so on until the demand and supply is not balanced.

\section{System States}

Here we use the notation $P_{M G C C}$ is the power of microgrid central controller power from connected from main utility and $P_{L C}$ is power generated by the local controller from own connected renewable energy resources. $P_{\text {Demand }}$ represents the power demand of connected load.

\section{Case I:}

$$
P_{L C}>P_{\text {Demand }}
$$

In this case local controller sends a request to main utility by using Micro grid central controller through the TCP/IP protocol for power supply.

\section{Case II:}

$$
P_{L C}<P_{\text {Demand }}
$$

If the power generated by the local controller than the power demand then Local controller sends a request to Micro grid central controller for required power. Then system equations as fallows

\section{Case III:}

$$
P_{L C}+P_{M G C C} \geq P_{\text {Demand }}
$$

In this case the micro-gird central controller will perform the intelligent load shedding with the help of Local controller.

\section{Benefits of Demand Response in Micro-Grids}

- The most promising feature of MG is the establishment of business industry that can worth millions and billions of dollars for providing backup power and support to the masses. With the well equipped setup it is capable of exporting the power to utilize and to some required residential areas as well as to some private sector. Thus, it provokes thirsty businessmen to invest money in this sector and can earn healthy profit. For example in a certain community of 10 - 15 houses there exists an MG setup and each owner of the house has to buy a membership of MG for backup power. So, in case of failure of delivery from utility MG provides its members quality power for certain time. Each member has to pay to MG owner who gains profit through exporting power to residential sector and in utility in times of need. In economics module of formulating the participation of Customer in Demand Response Program shows customer demand varies according to tariff rates and customer is benefited [12].

- The concept of demand response in micro-grids minimizes a lot of risks to electrical utilities. These risks 
include fault occurring in central plant, in trans- mission lines, in MG. Thus, it adds a security feature to utility while operating in non-autonomous mode as it is capable of operating in an island mode. During heavy loading conditions MG can be subjected to intentional or emergency islanding. Other types of risks include load forecasting, prices of the fuel regularity issues etc. MG smaller units requires less project capital and lead time compared to large and heavy utility units. Demand Response is a useful tool at a time of high wholesale market price less power consumption [13].

- Rapid increment of power demand has made the need of Demand response more attractive for system operators and customer [14].

MG provides supporting and control services to utilize such as:

1) By the injection/absorption of reactive power for controlling the voltage of the grid.

2) Can act as spinning reserve.

3) Can provide network stability.

4) Avoid system blackouts.

5) By the control of regulation etc. [15].

\section{Conclusion}

In modern lifestyle, the demand for energy is increasing rapidly day by day and production is increasing with respect to demand increment. So in modern power systems, we must also emphasize the energy management system to fulfill the rapidly increasing demand of energy to the smooth run of industrial and domestic loads. Demand response in micro-grid is a new emerging technology which can play numerous and important rules in world's energy demand and effective load management technique provides an opportunity to overcome the energy imbalance. The demand response technique also provides opportunity to fulfill the demand of different connected loads in the peak and normal hour of consumption. Demand response in non-autonomous microgrid technique improves power quality which is beneficial to people and ensures the interpretable power supply to load. It fit for crucial places such as hospitals, universities, defense intuitions etc.

\section{REFERENCES}

[1] B. Renders, L. Degroote, J. Driesen and L. Vandevelde, "Profits of Power-Quality Improvement by Residential Distributed Generation," 42nd International Universities Power Engineering Conference, 4-6 September 2007, pp. 377-381. doi:10.1109/UPEC.2007.4468976

[2] P. A. Daly and J. Morrison, "Understanding the Potential Benefits of Distributed Generation on Power Delivery Systems,” Rural Electric Power Conference, Little Rock,
29 April-1 May 2001, pp. 211-213.

[3] V. H. M. Quezada, J. R. Abbad and T. G. S. Roman, “Assessment of Energy Distribution Losses for Increasing Penetration of Distributed Generation," IEEE Transactions on Power Systems, Vol. 21, No. 2, 2006, pp. 533540. doi:10.1109/TPWRS.2006.873115

[4] P. M. Costa and M. A. Matos, "Reliability of Distributed Networks with Micro Grids,” IEEE Russia PowerTech, St. Petersburg, 27-30 June 2005, pp. 1-7.

[5] J. O. Anduaga, S. Macedo and J. Ruela, "MICROGRIDS: Large Scale Integration of Micro-Generation to Low Voltage Grids,” Technical Report, Micro-Grids Project Consortium, 2005.

[6] N. Hatziargyriou, A. Dimeas and A. Tsikalakis, "Hierarchical and Distributed Control Strategies for Micro-Grids," International Journal of Distributed Energy Sources, Vol. 1, No. 3, 2005.

[7] A. Maiorano, R. Sbrizzai, F. Torelli and M. Trovato, "Intelligent Load Shedding Schemes for Industrial Customers with Cogeneration Facilities,” Power Engineering Society 1999 Winter Meeting, Vol. 2, No. 31, 1999, pp. 925930.

[8] D. Novosel and R. L. King, "Using Artificial Neural Networks for Load Shedding to Alleviaie Overloaded Lines," IEEE Transactions on Power Delivery, Vol. 9, No. 1, 1994, pp. 425-433. doi:10.1109/61.277714

[9] L. J. Shih, W. J. Lee, J. C. Gu and Y. H. Moon, “Application of df/dt in Power System Protection and Its Implementation in Microcontroller Based Intelligent Load Shedding Relay,” Industrial and Commercial Power Systems Technical Conference, Memphis, 6-9 May 1991, pp. 1117.

[10] W. Lee and J. C. Gu, “A Microcomputer-Based Intelligent Load Shedding Relay,” IEEE Transactions on Power Delivery, Vol. 4, Nov. 4, 1989, pp. 2018-2024. doi:10.1109/61.35626

[11] R. Lasseter, A. Akhil, C. Marnay, J. Stephens, J. Dagle, R. Guttromson, A. Meliopoulos, R. Yinger and J. Eto, "White Paper on Integration of Distributed Energy Resources. The CERTS Micro Grid Concept,” Consortium for Electric Reliability Technology Solutions (CERTS), 2002, Technology Report LBNL-50829.

[12] H. Aalami, G. R. Yousefi and M. P. Moghadam, "Demand Response Model Considering EDRP and TOU Programs," IEEE/PES Transmission and Distribution Conference \& Exhibition, Chicago, 21-24 April 2008, pp. 1-6.

[13] M. H. Albadi and E. F. El-Saadany, "Demand Response in Electricity Markets: An Overview,” IEEE Power Engineering Society General Meeting, Tampa, 24-28 June 2007, pp. 1-5.

[14] US Department of Energy, "Benefits of Demand Response in Electricity Markets and Recommendations for Achieving Them," 2006.

[15] M. Qamaraza, S. M. Ali, A. Rasheed and Azam-ul-Asar, "Major Prospectus of Non-Autonomous Microgrid in Modern Power Systems," Power Generation and Renewable Energy Technologies, 2010. 